\title{
Program level of nursing students and the achievement of intercultural sensitivity after service learning experiences
}

\author{
Catherine S. Thomas, Leona Konieczny \\ Central Connecticut State University, United States
}

Received: September 18, 2017

Accepted: December 14, 2017

Online Published: December 21, 2017

DOI: $10.5430 /$ cns.v6n2p73

URL: https://doi.org/10.5430/cns.v6n2p73

\begin{abstract}
Nursing students require education and experience to develop cultural competence. Cultural sensitivity is a step on the journey to cultural competence. Nursing curricula vary regarding when and how to promote cultural sensitivity. Service learning (SL), is an experiential pedagogical method, which provides the opportunity to communicate and interact with persons from various cultures. A descriptive pilot study was undertaken in order to examine whether the program level affects the intercultural sensitivity of nursing students exposed to SL. The original Intercultural Sensitivity Scale (ISS) was used to assess intercultural sensitivity. In a paired samples $t$ test, two statements in the ISS relating to Interaction Confidence $(p=.006)$ and Respect for Cultural Differences $(p=.002)$ demonstrated junior level students had increased intercultural sensitivity scores when compared with sophomore level students' scores. This study may provide guidance to nursing faculty in determining at which level of students who will have maximal gain from SL.
\end{abstract}

Key Words: Service learning, Nursing students, Cultural competence

\section{INTRODUCTION}

\subsection{Supporting development of cultural competence in} nursing students

At every level of all nursing programs, students must be supported in their journey towards achieving cultural competence, which continues after they transition to professional practice. Stakeholders consistently agree that nurses should possess cultural knowledge, awareness and sensitivity in order to be culturally engaged. When nurses fully employ their cultural knowledge and skills, their ability to provide safe, effective care to diverse populations is enhanced. Since there is widespread recognition of this, it is imperative to support students in this journey. Implementation of various teaching methodologies with the intent of building a foundation of cultural competence have commonly been incorporated into nursing programs across the entire degree program. ${ }^{[1]}$ Cultural competence has a strong presence in nursing education, evidenced by many studies over time that have been conducted to evaluate the attainment of various aspects of cultural competency in nursing students. The large majority of those studies assessed cultural awareness after an implementation of specific interventions and teaching methods introduced in certain class settings or throughout the entire program. ${ }^{[2]}$ To date, there is no consensus in nursing education regarding the most effective learning pedagogies for cultural competency. An example of a teaching method that often includes opportunities for students to encounter many cultural concepts, is the learning pedagogy of service learning (SL). Experiencing SL engages students both in their process of learning and reflection about what it means to

*Correspondence: Catherine S. Thomas; Email: csthomas@ @csu.edu; Address: Central Connecticut State University, United States. 
be an engaged citizen. ${ }^{[3]}$ SL has become commonplace in higher education settings throughout the United States (US). The current literature has indicated that there are numerous benefits for students who engage in SL. ${ }^{[4]}$

That current literature has defined SL in various ways. For this study, the working definition is; a pedagogical method that is experiential, with the purpose of supporting the attainment of university and program outcomes through structured mutually beneficial learning activities. ${ }^{[5,6]}$ SL experiences of fer students opportunities to experience cultural interactions and increase the students' level of civic awareness. Incorporation of debriefing sessions allows students the opportunity of faculty support during students' exploration of preconceptions that they may have held before their participation in SL activities and promotes self-reflection. ${ }^{[4,7]}$

The purpose of this research study was to evaluate if there were differences that existed between two program levels of students; sophomores and juniors who participated in two national based SL experiences, both of which highlighted the significance of service to vulnerable populations and in creasing the students' level of civic awareness. While the locations, length and types of service activities were not similar, the primary objective for both SL experiences was to provide care and service to vulnerable populations in regions of the US that have distinct differences than the location region of the University.

\subsection{Connection of SL to department and university mis- sions}

The SL experiences realized the ethos of department of nursing and the university. There are four elements of distinction contained within the mission for the public state university, one of which is community engagement, the purpose of which is to promote higher level learning as well as cultural understanding. The university mission states the commitment is to prepare "students to be thoughtful, responsible and successful citizens". ${ }^{[8]}$ The mission of the nursing department is harmonious with that purpose, for the students and graduates are expected to develop their social consciousness and eventually make contributions to society through their nursing care. ${ }^{[8]}$ Both SL experiences also aligned with key components that are expressed throughout the nursing program outcomes. Those components focus on producing graduates who are educated to embrace and embody the professional nursing values of human dignity, integrity, lifelong learning, and social justice When graduates embody those values, they are better prepared to promote the health status of individuals, assist in the prevention of illness and the minimization of complications for all members of society, especially those who are identified as being part of vulnerable populations. ${ }^{[8]}$ Promoting the concept of lifelong service as a professional nurse especially for persons belonging to vulnerable populations, is an important ethos within the faculty of nursing.

\subsection{Structure and differences in the SL experiences}

The initial SL experience occurred over a long weekend at the end of the spring semester. During which a small group of junior level students were able to focus on the challenges related to public health needs of people without health care insurance coverage and/or access in eastern Tennessee (TN) as part of a free temporary clinic operated by a not-for profit volunteer organization. The second SL experience occurred during the subsequent academic year occurred over six days during the spring break, during which a small group comprised of sophomore and junior level students who were able to focus on learning about and/or meeting the public health needs of persons experiencing societal and socioeconomic challenges in various settings using several different approaches. The experiences were jointly planned by the lead faculty person and two not-for profit volunteer coordination organizations in New Orleans, Louisiana (NOLA). Both SL experiences were exclusive from nursing courses, and were not used as a replacement for or as a required clinical assignment. The activities and opportunities provided during both SL experiences allowed students to engage in four out of six crucial learning elements for SL. ${ }^{[9]}$ Students were able to experience: a diversity of interactions, community activities, civic competencies and critical reflection. Both SL experiences also offered the students an opportunity to become familiar with experiential philanthropy.

\subsection{Literature review of SL}

Current literature demonstrates that experiential philanthropy helps some categories of learners to foster an appreciation of current issues in society. ${ }^{[10]}$ Those categories of students include; female, upperclassmen, and those who are majoring in helping professions demonstrated a greater benefit from SL than other categories of students. ${ }^{[10]}$ The categories described in the literature correlate with categories of students in nursing. In addition, this study detailed the perceptions of participants regarding SL might be positively influenced by connections and interactions with both their group members and faculty. ${ }^{[10]}$ SL was shown to have positive benefits for learning outcomes for students. ${ }^{[1]}$ Other types of positive outcomes for students has been demonstrated in literature assessing the related concepts of civic engagement and social development in students participating in course based SL experiences. The qualitative component of the study reported that the students sensed their social empowerment had been strengthened. The authors suggest from their results 
that there is a connection between the length of guided selfreflection and the sense of social empowerment. They call for continued study about which aspects of SL affect social empowerment and related concepts are the most effective and enduring. ${ }^{[12]}$

Attention to the potential gains from SL for students in several helping professions is apparent in current literature, from discussing the impact of SL on public health students, ${ }^{[7]}$ and demonstration of improvements in measures of cultural competence in physical therapy students. ${ }^{[13]}$ For nursing education, the recent literature has focused on identifying perceptions of student nurse needs related to the preparation for SL experience. ${ }^{[5,7]}$ Those current studies about SL in other helping professions did not assess the extent of the advantages either systematically and/or empirically. The studies did reveal advantages that range from improved grade point averages to measures of civic responsibility along with life competencies. $^{[14]}$

One review of the literature in nursing education about $\mathrm{SL}^{[15]}$ concluded that further research was essential. The authors propose there is considerable potential relative to inspiring social change, providing students to welcome fulfillment in their embodiment as a change agent, to experience diversity in alternate situations, and to develop into actively socially engaged citizens. One of the recommendations included debriefing as a planned part of SL experiences to address any emotional responses by the students. The differences in emotional response may be related to nursing students having variations in their life experiences and developmental level achievement. The literature in nursing education on SL has developed further since the publication of that review of literature. A 2013 qualitative study by Schofield et al identified that nursing students perceived SL as stimulating self conception, and contributed to learning to be a caring nurse along with their nursing identity ${ }^{[5]}$ and five quantitative studies from 2010 to $2016^{[14-18]}$ on SL that were conducted using different measurement instruments focusing on numerous variables identified increases in: civic engagement scores, cultural efficacy scores, cultural competence scores, viewpoints concerning homelessness, leadership abilities as well as social justice awareness for nursing students. A mixed methods study described SL as having an impact on almost all of the cultural constructs measured and students reflected on the SL experience as positive, and that they perceived that their learning about language barriers as valuable. ${ }^{[19]}$

\subsection{Difference in intercultural sensitivity between pro- gram levels of students}

The hypothesis is that the program level of the students providing care to vulnerable populations in a culturally distinct region will have an impact on the level of intercultural sensitivity. Intercultural sensitivity is within the affective domain of intercultural communication. This pilot study investigates whether variances in intercultural sensitivity of nursing students based on the program level improves after the completion of SL.

\section{Methods}

The proposal was submitted to the university human studies council (institutional review board) and received approval. All participants were given both written and verbal explanations of the study.

The instrument used for this study was the Intercultural Sensitivity Scale (ISS), which was used to measure intercultural sensitivity which is part of the affective dimension of intercultural communication competence, and was developed by Chen and Starosta, ${ }^{[20]}$ the original version of the instrument has a total of 24 items, structured and scored as a Likert-type scale extending from 1 (strongly disagree) to 5 (strongly agree) to assess the five elements of intercultural sensitivity which are: interaction engagement (total of 7 items), respect for cultural difference (total of 6 items), interaction confidence (total of 5 items), interaction enjoyment (total of 3 items), and interaction attentiveness (total of 3 items). The instrument authors granted their permission for use of this instrument for this study. The reliability coefficient is listed at $0.86-0.88$ for the original instrument.

\subsection{Design}

Before students commenced their SL experiences, the researchers obtained written consent from the participants. All participants were given a brief demographic characteristics sheet along with the study instrument which were prior to the SL experiences. On return from the SL experiences, the participants completed the study instrument a second time.

\subsection{Setting}

This program of study in nursing is taught from a university situated in the Northeast portion of the US. The initial SL experience was in one location in eastern Tennessee that is part of the Appalachian region. ${ }^{[21]}$ That area of Tennessee has a high overall poverty level of $20.6 \%$, and $17.6 \%$ of the area populace who are 65 years and under who do not have health insurance coverage. ${ }^{[21]}$ The second SL experience occurred in several locations in and around New Orleans, Louisiana. The poverty rate in New Orleans is 27\%. [21] The homeless rate in Greater New Orleans spiked after Hurricane Katrina. The current homeless rate is at $46.9 / 10,000$ which is the $4^{t h}$ highest rate in the US. ${ }^{[2]}$ In contrast, the portion of the US where the university is located has an overall poverty rate of 
$12.2 \%$ of the area population and for minors an overall rate of $17.9 \%$. For those 65 years old and under who do not have health insurance coverage the overall rate is $10.3 \% .^{[21]}$ The level of homelessness for the entire state is $11.3 \%$ where the university is located is much lower than New Orleans as well as the national average. ${ }^{[22]}$ The areas of SL experiences had an increased rate of homelessness and a decreased rate of persons with health insurance coverage as compared to the location of the nursing program.

\subsection{Sampling procedures}

The convenience sample consisted of the selected nursing students who participated in either SL experience. Due to limited space and financial constraints, the sample size was limited. Students had to submit an application to attend the SL experiences, through a personal narrative describing their motivation and objectives for undertaking SL. The selection process consisted of a blinded review. A total of 16 participants were selected for this study, their results were analyzed from the two groups. From the first group, only participants who filled in pre and post SL instruments were included for analysis ( $(=9)$, and the second group that attended the second SL experience, comprised of both sophomore $(\mathrm{n}=2)$ and junior level students $(\mathrm{n}=5)$ for a total $\mathrm{n}=7$ were included, all of whom completed the instrument pre and post the experience.

\subsubsection{Demographic variables of sample}

Participants provided information about their: gender, age, race/ethnicity, born in US or not, if they had lived outside the state where the university was located, experience working in healthcare (not including program required clinical sections), community based volunteer experience, if they encountered the opportunity to travel outside of the state, or if they had also had completed any travel outside of the US.

\subsubsection{Research design}

This was a quantitative comparative study comparing the pre and post intercultural sensitivity scores of sophomore and junior program level nursing students who participated in two different non-course based SL experiences.

\section{RESUlts}

The ISS was scored as per the authors' instructions. Data were utilized from participants who had completed every item on the ISS both pre and post both SL experiences. The analysis of data was completed utilizing the Statistical Package for the Social Sciences (SPSS) version 22.0.

The SL groups were very similar in demographic characteristics. All of the TN participants $(n=9)$ were female, age range was $21-37$ years, and the mean age was 23.67 , median was 22, and mode was 21. A small number of the participants (2) had lived out of state $(22.2 \%)$, the remainder (7) had not lived out of state (77.8\%). Almost half of the participants in the TN group did have healthcare work experience (44.4\%). The majority of the participants did have prior community volunteer experience ( $88.9 \%)$. Every participant had experience with traveling out of the state, and 7 of the 9 participants $(77.8 \%$ ) had experience with travel outside of the US. The entire group of NOLA participants were female $(n=7)$. The median and mode for age range was 21-29. A small number of the 7 participants had lived out of state (28.6\%), and 5 remaining had not lived outside of the state $(71.4 \%)$. Three participants had healthcare work experience $(42.9 \%)$. All (100\%) of the participants in the NOLA group had previous volunteer experience. All of the NOLA participants had traveled outside of the state, and 4 $(57.1 \%)$ had traveled outside of the United States.

Demographic characteristics were examined for each student according to their program level. For sophomore students, 1 student was in the 18-20 age range and one student was in the 30-39 age range. For junior students, 1 (7.1\%) was in the 18-20 age range, 10 (71.4\%) were in the 21-29 age range, $2(14.3 \%)$ were in the $30-39$ age range and $1(7.1 \%)$ was in the 40-49 age range. Please see Table 1 for other demographic characteristics organized by program level.

Table 1. Demographic characteristics by program level

\begin{tabular}{lll}
\hline & Sophomore & Junior \\
\hline \multirow{2}{*}{ Lived Out of State } & Yes 1 $(6.3 \%)$ & Yes 3 $(18.8 \%)$ \\
& No 1 $(6.3 \%)$ & No 11 $(68.8 \%)$ \\
Healthcare Work Experience & Yes 1 $(6.3 \%)$ & Yes 8 $(50 \%)$ \\
& No 1 $(6.3 \%)$ & No 6 $(37.5 \%)$ \\
Previous Volunteer Experience & Yes 2 $(12.5 \%)$ & Yes 13 $(81.3 \%)$ \\
& No 0 $(0 \%)$ & No 1 $(6.3 \%)$ \\
Travel Out of State & Yes 2 $(12.5 \%)$ & Yes 14 (87.5\%) \\
& No 0 $(0 \%)$ & No 0 $(0 \%)$ \\
Travel Out of US & Yes 1 $(6.3 \%)$ & Yes 10 $(62.5 \%)$ \\
& No 1 $(6.3 \%)$ & No 4 $(25 \%)$ \\
\hline
\end{tabular}

For all participants in both groups, the pre and post item analyses were completed by conducting paired sample $t$-tests. There are two statements that demonstrated statistical difference showing the junior level students have increased intercultural sensitivity scores after a SL experience as compared to sophomore level students. Please see Table 2 to review the results of the paired samples $t$-test $(p<.05)$.

For the component of interaction confidence, there was an additional statement of interest. Item number 4: "I find it very hard to talk in front of people from different cultures", which had a $p$-level of .012 . While this statement did not demonstrate significance. It reaffirms that the program level of student partially impacts interaction confidence. 
Table 2. Pre and post SL ISS paired samples $t$-test

\begin{tabular}{ll}
\hline ISS statement & $p$-value \\
\hline Interaction Confidence: & .006 \\
6. I can be as sociable as I want when interacting with people from different cultures. & .002 \\
\hline Respect for Cultural Differences: & \\
18. I would not accept the opinions of people from different cultures. & \\
\hline
\end{tabular}

\section{Discussion}

There were statistically significant differences for two of the items on the ISS involving interaction confidence and respect for cultural differences. These results align with the expectation for nursing students to develop a foundation of cultural competence. The identified differences were not related to demographic characteristics as the groups were homogeneous. However, other influencing factors should be considered. These factors include but are not limited to nursing and general education course content, clinical experiences provided within the nursing curriculum, and maturity of the student.

In the nursing program curriculum, students are introduced to cultural competence, professional nursing identity along with therapeutic communication are introduced during the first semester of the program, which is the fall of their sophomore year. It is important to note that those students have only one laboratory experience in the fall semester. In the spring semester they have two clinical experiences which differ in the type of patient care delivered. For the junior year students complete two additional eight week clinicals during the fall in Maternity and Psychiatric/Mental Health settings, and they complete a 15 week clinical experience in acute care Medical Surgical settings during the spring semester.

The result with item 6 on the ISS demonstrates that the junior level students perceived a positive change in their ability to socialize with people from other cultures. This may strengthen their interactions and ability to fulfill many components of the nursing process. The result with item 18 demonstrates that the junior level students were able to recognize the importance of a non-judgmental perspective when considering the opinions of people from other cultures, which is vital to forming a trust relationship.

One of the strengths for this descriptive pilot study is that it builds upon the small amount of existing studies about local and national based SL experiences. Another strength of this pilot study is measurement in the affective domain of learning. Nursing students may benefit from development of attitudes in addition to acquiring knowledge and skills. This pilot study is only the second study to assess nursing students using the ISS instrument. It has been used with university students in communications and business. The findings support the concepts of respecting cultural differences and feeling confident during interactions. This confirms that previous studies findings in both nursing and higher education that there are benefits to SL for students. Many nursing students may not have resources that allow for international travel and/or SL experiences. A national based approach may help students towards their journey of cultural competence. No studies in nursing education to date have examined for differences between program levels of students. This pilot study may provide guidance for nursing faculty and stakeholders in determining which program level student in their programs might gain the maximal benefit relating to SL experiences with culturally distinct populations. Funding, student selection and scheduling limitations continue to be considerations and potential barriers during the planning and implementation phases. The findings of this study may assist with decision making of nursing faculty related to SL. The results of the pilot study may be used to examine intercultural sensitivity at the start and end of the nursing program to assess for differences in affective learning.

There are some study limitations. With limited funding and volunteer organization guidelines controlling the amount of attendees, the sample size is small. This is most often the case with SL experiences across all types and sizes of nursing programs. Both groups completed an orientation to the SL experience prior to departure as well as formal and informal debriefings during and after return. While potentially impacting the results, the need to establish behavior expectations as stewards of nursing and the nursing program and allowing students to process their experiences as a group were of higher priority. Both groups also had several opportunities to experience local cultural offerings, with variances between the two trips as well as within the groups on the same trip.

This pilot study supports the benefit, and the need for nursing programs to provide SL opportunities which incorporate cultural encounters in order for students to practice their cultural skills to develop their intercultural competence. Previous research highlights paucity in literature related to the benefits of SL in improving cultural competence. ${ }^{[2,23,24]}$ The inves- 
tigators intend to expand upon the statistically significant findings identified in this descriptive pilot study. Future SL experiences will continue to include students from all levels of the program. Future groupings of students completing the varying SL experiences and activities will intentionally include all program levels of students because SL has been demonstrated to improve the intercultural awareness of all program level nursing students.

\section{ACKNOWLEDGEMENTS}

The authors acknowledge the support from the Chair of the Department of Nursing, Dr. M. Levvis, the Student Activities and Leadership Development Department, and the 2016-2017 board members from the Student Nurses Association.

\section{CONFLicts OF InTEREST Disclosure}

The authors declare they have no conflicts of interest.

\section{REFERENCES}

[1] Thomas CS, Konieczny L. Impact of a Service Learning Experience on the Intercultural Sensitivity of Nursing Students. Clin Nurs Stud. 2017; 5(2): 1-5. https://doi.org/10.5430/cns.v5n2p41

[2] Byrne D. Cultural Competency in Baccalaureate Nursing Education: A Conceptual Analysis. International Journal for Human Caring. 2016; 20(2): 114-119. https://doi.org/10.20467/1091-571 $0-20.2 .114$

[3] Levesque-Bristol C, Knapp TD, Fisher BJ. The Effectiveness of Service-Learning: It's Not Always What You Think. Journal of Experiential Education. 2010; 33(3): 208-224. https ://doi .org/10 .5193/JEE33.3.208

[4] Toncar MF, Reid JS, Burns DJ, et al. Uniform assessment of the benefits of service learning: the development, evaluation, and implementation of the SELEB scale. Journal of Marketing Theory and Practice. 2006; 14: 223-238. https://doi.org/10.2753/MTP1 069-6679140304

[5] Schofield R, Allan M, Jewiss T, et al. Knowing self and caring through service learning. Int J of Nurs Educ Scholarsh. 2013; 10(1): 267-274. PMid: 24317787. https://doi.org/10.1515/ijne s-2013-0009

[6] Bandy J. What is Service Learning or Community Engagement? 2016 [Cited 2017 Aug 11]. Available from: https://cft.vander bilt.edu

[7] Stallwood LG, Groh CJ. Service-learning in nursing curriculum: Are we at the level of evidence-based practice? Nurs Educ Perspect. 2011 September/October; 32(5): 297-301. PMid: 22029240. https://doi.org/10.5480/1536-5026-32.5.297

[8] Central Connecticut State University. New Britain: Central Connecticut State University; 2016 [cited 2017 Aug 11].

[9] Hahn T, Hatcher J, Price M, et al. IUPUI Taxonomy for Service Learning Courses. C2015 [cited 2017 Aug 11]. Available from: https://scholarworks. iupui.edu

[10] McDougle L, McDonald D, Li H, et al. Can Philanthropy Be Taught? Nonprofit Volunt Sect Q. 2016; 1-22.

[11] Warren JL. Does Service-Learning Increase Student Learning? A Meta-Analysis. Michigan Journal of Community Service Learning 2016; 18(2): 56-61.

[12] Knapp T, Fisher B, Levesque-Bristol C. Service-Learning's Impact on College Students' Commitment to Future Civic Engagement, Self-
Efficacy, and Social Empowerment. J of Community Pract. 2010; 18 : 233-251.https://doi.org/10.1080/10705422.2010.490152

[13] Denton JM, Esparza S, Fike DS, et al. Improvements in Cultural Competence Through Classroom and Local Cross-Cultural ServiceLearning Activities. J Phys Ther Educ. 2016; 30(2): 6-13.

[14] Long T. Influence of International Service Learning on Nursing Students' Self-Efficacy Towards Cultural Competence. J Cult Divers. 2016; 23910: 8-33.

[15] Gillis A, Mac Lellan M. Service Learning with Vulnerable Populations: Review of the Literature. J Nurs Scholarsh. 2010; 7(1): 1-27. https://doi.org/10.2202/1548-923X. 2041

[16] Lowenson KM, Hunt RJ. Transforming Attitudes of Nursing Students: Evaluating a Service-Learning Experience. J Nurs Educ. 2011; 50(6): 345-349. PMid: 21524020. https://doi.org/10.3928/ 01484834-20110415-03

[17] Groh CJ, Stallwood LG, Daniels JJ. Service Learning in Nursing Education: Its Impact on Leadership and Social Justice. Nurs Educ Perspect. 2011; 2(6): 400-405. https://doi .org/10.5480/1536 $-5026-32.6 .400$

[18] Amerson R. The Impact of Service-Learning on Cultural Competence. Nurs Educ Perspect. 2010; 31(1): 18-22. PMid: 20397475.

[19] Chen HC, McAdams-Jones D, et al. The impact of service-learning on students' cultural competence. Teaching and Learning in Nursing. 2012; 7: 67-73. https://doi.org/10.1016/j.teln.2011.11 .002

[20] Chen GM, Starosta WJ. The development and validation of the intercultural sensitivity scale. Human Communication. 2000; 3: 1-15.

[21] United States Census Bureau [Internet]. US Department of Commerce; no date [cited 2017 Aug 11]. Available from: http://www. census.gov

[22] National Alliance to End Homelessness. The State of Homelessness in America. C2016 [Cited 2017 Aug 12]. Available from: https://endhomelessness.org

[23] Shen Z. Cultural competence models and cultural competence assessment instruments in nursing: A literature review. J Transcult Nurs. 2015; 26(3): 308-321. PMid: 24817206. https ://doi .org/10.1 $177 / 1043659614524790$

[24] Mareno N, Hart PL. Cultural competency among nurses with undergraduate and graduate degrees: Implications for nursing education. Nurs Educ Perspect. 2014; 35(2): 83-88. https ://doi .org/10.5 480/12-834. 1 